AperTO - Archivio Istituzionale Open Access dell'Università di Torino

\title{
How I treat patients with systemic sclerosis in clinical practice
}

\section{This is the author's manuscript}

Original Citation:

Availability:

This version is available http://hdl.handle.net/2318/1647997

since 2019-02-11T16:24:48Z

Published version:

DOI:10.1016/j.autrev.2017.07.018

Terms of use:

Open Access

Anyone can freely access the full text of works made available as "Open Access". Works made available under a Creative Commons license can be used according to the terms and conditions of said license. Use of all other works requires consent of the right holder (author or publisher) if not exempted from copyright protection by the applicable law. 


\section{IIIS AperTO}

UNIVERSITÀ

DEGLI STUDI

DI TORINO

This is the author's final version of the contribution published as:

Daniela Rossi, Elisabetta Zanatta, Piero Marson, Savino Sciascia, Pamela Polito, Dario Roccatello, Franco Cozzi . HOW I TREAT PATIENTS WITH SYSTEMIC

SCLEROSIS IN CLINICAL PRACTICE. Autoimmun Rev. 2017 Oct;16(10):1024-

1028. doi: 10.1016/j.autrev.2017.07.018

The publisher's version is available at:

https://www.sciencedirect.com/science/article/abs/pii/S156899721730201X?via $\% 3$ Dihub

When citing, please refer to the published version.

\section{Link to this full text:}

http://hdl.handle.net/2318/1647997 
HOW I TREAT PATIENTS WITH SYSTEMIC SCLEROSIS IN CLINICAL PRACTICE.

Daniela Rossi1,2, Elisabetta Zanatta3, Piero Marson4, Savino Sciascia1,2, Pamela Polito3, Dario Roccatello1,2, Franco Cozzi3

1-Center of Research of Immunopathology and Rare Diseases - Coordinating Center of the Network for Rare Diseases of Piedmont and Aosta Valley, Department of Clinical and Biological Sciences and University of Turin

2. SCU Nephrology and Dialysis Unit, S. Giovanni Bosco Hospital and University of Turin, Turin, Italy

3.Rheumatology Unit, University Hospital, Padua, Italy

4. Apheresis Unit, University Hospital, Padua, Italy 


\section{$\underline{\text { Abstract }}$}

Systemic sclerosis (SSc) or scleroderma is a disorder of the connective tissue affecting the skin, and it is often associated with visceral involvement. The predominant pathological features of SSc are autoimmunity, vasculopathy, and fibrosis. Progressive fibrosis is associated with changes in the microcirculation of the involved organs. Here, we review the clinical features of systemic sclerosis and describe the best practice approaches for its management, reviewing available guidelines and recommendations and providing experts' insights. 


\section{$\underline{\text { Introduction }}$}

Systemic sclerosis (SSC) or scleroderma is an autoimmune disorder of the connective tissue affecting the skin that is often associated with visceral involvement. It is characterized by excessive collagen deposition in the skin and internal organs, resulting in progressive tissue fibrosis and with changes in the microcirculation leading to secondary Raynaud's phenomenon and obliterative vasculopathy.

Overall, the estimated prevalence is 25 cases/100,000, the incidenceis $0.06-1.9$ years/100,000, and it is prevalent in females (mean 4:1). In detail, prevalence ranges from $0.7 / 100,000$ to $53 / 100,000$ depending on demographics and the country of residence, with higher numbers in the USA as compared to Europe or Japan. Age at onset is between 35 and 65 years $(1,2)$.

Pathogenesis is multifactorial and includes genetic factors such asHLA (HLA A1, B8, DR1, DR3, DR5, DR11), and environmental factors such as viruses (Cytomegalovirus, parvovirus B19), ortoxic substances (silica, silicone prostheses, polyvinyl, benzene, organic solvents, certain drugs, adulterated rapeseed oil)(1,2).

SSc has a highly variable evolution, ranging from the acral-localized form to rapid swelling lesions that spread quickly to all areas of the skin including the trunk, and to the visceral involvement (3).

SSc frequently affects internal organs such as the lungs, heart and the gastrointestinal tract (GI), all of which significantly contribute to morbidity and reduced quality of life in these patients. Overall, the prognosis of scleroderma is influenced by visceral involvement (especially of the lung), as well as cardiac and renal involvement. 
Even if survival has improved considerably in the last thirty years, SSc has one of the highest mortality rates among the rheumatic diseases. Cumulative survival following diagnosis has been estimated $74.9 \%$ at 5 years and $62.5 \%$ at 10 years. The common causes of death are pulmonary fibrosis and pulmonary arterial hypertension (PAH) (4).

\section{Overview of Current Guidelines and Recommendations}

SSc therapy is still difficult to manage and yet is not well defined. It must consider the various pathways involved in the disease: activation of T lymphocytes, vascular disease due to vasospasm and endothelial immune damage, and abnormal stimulation of fibroblasts resulting in excessive deposition of extracellular matrix. Therefore, SSc therapy includes steroid and immunosuppressants, vasoactive drugs (vasodilators and endothelial protectors), and anti-fibrotic agents. $(5,6)$

The EULAR has published in 2016 updated evidence-based, consensus-derived recommendations for the treatment of SSc (7).

As compared to the previous (2009) EULAR recommendations for the treatment of SSc, the updated recommendations include several new therapies for specific SSc-related organ involvement. The greatest changes have been made inthe treatment of vascular complications. These changes include the introduction of phosphodiesterase type 5 (PDE5) inhibitors for SSc-related RP and digital ulcers (DUs), riociguat and new aspects of endothelin receptor antagonists (ERAs), prostacyclin analogues and PDE5 inhibitors for SSc-related PAH. New recommendations regarding the use of fluoxetine for SSc-related RP were also added. 
The task force consisted of 32 SSc clinical experts from Europe and the USA. All the EULAR Scleroderma Trials centers and research groups were invited to submit and select clinical questions concerning SSc treatment using a Delphi approach. Accordingly, 46 clinical questions addressing 26 different interventions were selected fora systematic literature review. The new recommendations were based on the available evidence andwere developed during a consensus meeting with clinical experts and patients. The procedure resulted in 16 recommendations being developed (instead of 14 in 2009) that address the treatment of several SSc-related organ complications: Raynaud's phenomenon, digital ulcers, pulmonary arterial hypertension, skin and lung disease, scleroderma renal crisis and gastrointestinal involvement.

In Raynaud's phenomenon, a meta-analysis of randomized control trials (RCTs) on dihydropyridine-type calcium antagonists indicates that nifedipine (9-16) and PDE5 inhibitors (Sildenafil, Tadalafil, Vardenafil) (16-22) reduce the frequency and severity of SSc-RP attacks. Oral nifedipine with PDE5 should be considered as first-line therapy for SSc-RP. A meta-analysis of RCTs on prostanoids indicates that intravenous iloprost reduces the frequency and severity of SSc-RP attacks. Intravenous iloprost should be used for the treatment of SSc-RP attacks after oral therapy. Fluoxetine may also improve SSc-RP attacks (23).

In digital ulcers in patients with SSc: Two RCTs indicate that intravenous iloprost is effective in healing digital ulcers in patients with SSc (24-25). A meta-analysis of RCTs and results of an independent RCT suggest that PDE5 inhibitors improve healing of digital ulcers in patients with SSc. 
In 2013, two meta-analyses compared i.v. iloprost, iloprost for oral use, trepronistil and beraprost. Authors reported that small sample sizes, few comparative trials, and heterogeneity limited the conclusions. However, the results suggested a role for PDE-5 inhibitors in the healing of digital ulcers; bosentan and i.v. iloprost may prevent their recurrences (26-28). Moreover, the results of a small RCT indicate that PDE5 inhibitors may prevent the development of new digital ulcers in SSc.

Lately, the efficacy of bosentan in reducing the number of new digital ulcers has been confirmed in two high-quality RCTs. Bosentan should be considered for reducing the number of new digital ulcers in SSc, especially in patients with multiple digital ulcers despite the use of calcium channel blockers, PDE5 inhibitors or iloprost therapy (2930).

In SSc-PAH: Several ERAs (ambrisentan, bosentan and macitentan) (31-33), PDE5 inhibitors (sildenafil, tadalafil) and riociguat have been approved for the treatment of $\mathrm{PAH}$ associated with connective tissue diseases (CTDs). One high-quality RCT on patients with SSc indicates that continuous intravenous epoprostenol improves exercise capacity, functional class and hemodynamic measures in SSc-PAH. Intravenous epoprostenol (2 $\mathrm{ng} / \mathrm{Kg} / \mathrm{min})$ should be considered for the treatment of patients with severe SSc-PAH (class III and IV) since improvement has been seen in the Walk Test, in NYHA, in the Borg dyspnea index, in pulmonary artery pressure (PAP), in right atrial pressure, and in Cardiac index (34).

Other prostacyclin analogues (iloprost, treprostinil) have also been registered forthe treatment of PAH associated with CTDs. Sitaxentan use has been discontinued due to hepatotoxicity. 
In Skin and lung disease: Two RCTs and their re-analysis have shown that methotrexate improves skin score in early diffuse SSc. Positive effects on other organ manifestations have not been established (35-38).

Cyclophosphamide should be considered for the treatment of SSc-related interstitial lung disease (ILD) (39-44).

Regarding hematopoietic stem cell transplantation (HSCT), two RCTs have shown improvement of skin involvement and stabilization of lung function in patients with SSc, while a third, large RCT reports improvement in event-free survival in patients with SSc as compared to cyclophosphamide-treated subjects. HSCT should be considered for the treatment of selected patients with rapidly progressive SSc at risk of organ failure. Given the high risk of treatment-related side effects and early treatmentrelated mortality, careful selection of patients with $\mathrm{SSc}$ for this kind of treatment and the experience of the medical team are of fundamental importance (45-46).

In scleroderma renal crisis (SRC): many studies have shown benefits in survival with the use of ACE inhibitors in patients with SRC. Experts recommend the immediate use of ACE inhibitors in the treatment of SRC (47-51). Glucocorticoids are associated with a higher risk of SRC; therefore blood pressure and renal function should be carefully monitored in these patients (52).

In SSc-related gastrointestinal disease: the experts recommend using proton pump inhibitors (PPIs) for the treatment of SSc-related gastroesophageal reflux disease (GERD) and the prevention of esophageal ulcers and strictures (53-57). Prokinetic 
drugs should be used for the management of SSc-related symptomatic motility disorders such as dysphagia, GERD, early satiety, bloating, pseudo-obstruction (58). Furthermore, experts recommend using intermittent or rotating antibiotics to treat symptomatic small intestine bacterial overgrowth in patients with SSc (59-60).

\section{Comments on the guidelines}

After reviewing all the above-stated topics together, some considerations are worth mentioning. Other therapies besides the previously listed ones have not been included due to the insufficient number of studies. Some further information has been published since the guidelines dissemination. This applies to:

a) Tocilizumab (162 mg/week subcutaneously) effective on the skin and lungs (61).

b) Mycophenolate mofetil compared to CYC in patients with SSc-ILD (62).

Lack of efficacy tests does not imply that efficacy is absent; thus the absence of a recommendation for a drug should not be interpreted as a contraindication for its use.

It is believed that these up-to-date recommendations will help improve the care of patients with SSc in an 'evidence-based' manner and may point to a direction for further clinical research.

Considering the complexity and heterogeneity of SSc and the limited evidence of the effectiveness of treatments, it is recommended that patients with systemic sclerosis be referred to specialized centers with appropriate management skills.

How I treat SSc: the experts' opinion-the Padua Experience 
The therapeutic approach to patients with Systemic Sclerosis (SSc) should be tailored to their clinical manifestations and laboratory findings. First, it is important to define the subset of SSc (i.e., diffuse or limited cutaneous form) [63] and the ANA specificity (anti-centromere, anti-topoisomerase I, anti-RNA polymerase III) [64].

The limited cutaneous form is the most common subset of SSc and is characterized by acral localized skin lesions (hand sclerodactyly and "scleroderma facies"). The main clinical manifestations in this form are ischemic skin ulcers and subcutaneous calcifications. Gastrointestinal symptoms are often present at an early stage, while other visceral involvement is not frequent and slowly evolving. The only exception is pulmonary arterial hypertension, which affects approximately $10 \%$ of patients and can appear many years after SSc diagnosis [65].

The diffuse cutaneous form on the other hand is clinically characterized by rapidly evolving skin lesions, ischemic ulcers, concomitantinflammatory manifestations (e.g.arthritis, tendonitis and myositis), and frequent internal organ involvement (pulmonary fibrosis, cardiomyopathy, scleroderma renal crisis, gastrointestinal disorders), resulting in a poor prognosis for many patients [66].

Raynaud's phenomenon is the onset manifestation in about95\% of SSc patients. Our first line treatment generally consists of oral vasodilators (especially calcium antagonists) at maximally tolerated dose [8], with the addition of intravenous iloprost therapy in case of severe Raynaud's phenomenon [25].

Cutaneous lesions in patients with diffuse SSc may spread within a few months from acrallocalized areas to almost the entire body surface, including the trunk. Given the 
fundamental role that immune-mediated inflammation plays in the pathogenesis of these lesions, we recommend initiating immunosuppressive therapy as soon as possible with either methotrexate or mycophenolate mofetil $[36,67]$. To potentiate the immunosuppressive therapy, SSc patients with rapidly progressive cutaneous involvement usually undergo long-term plasmaexchange in the Padua Rheumatology Unit [68] to "slow down" disease activity.

Ischemic ulcers affect nearly $50 \%$ of SSc patients in both cutaneous forms. Intravenous iloprost is the only therapy that has proven to be effective in healing skin ulcers [69]. We recommend the use of antibiotics in case of ulcer superinfection. Treatment with the endothelin receptor antagonist bosentan may help prevent and reduce the onset of new digital ulcers in SSc patients [30,70].

Skin ulcers may also arise from subcutaneous calcifications which can reach a considerable size ("tumoral calcinosis"), most notably in patients with the limited cutaneous form. Various drugs, such as colchicine and diltiazem, have been tested as a treatment for calcinosis though with poor results. Tumoral calcinosis often requires surgery [71].

The gastrointestinal tract is the internal organ most frequently involved in SSc, notably the distal esophagus. GERD requires treatment with PPIs to reduce gastric acidity and prevent esophagitis $[53,72]$. Prokinetic (promotility) drugs such as domperidone and metoclopramide have shown poor efficacy in alleviating GI symptoms (dysphagia, early satiety, abdominal distension, persistent constipation) [73]. Antibiotic rotation is very 
useful in preventing bacterial overgrowth which can cause recurring diarrhea and malnutrition in SSc patients [74].

The past fifteen years have seen the advent of new drugs offering substantial improvements in the treatment of PAH symptoms and hemodynamics [75]. Administration of the drugs requires a definitive diagnosis of PAH by cardiac catheterization. These novel agents include endothelin receptor antagonists, PDE5 inhibitors, prostacyclins and recently, riociguat (soluble guanylate cyclase stimulator) [76]. The NYHA functional class of the patient determines the choice of treatment (e.g. patients in class IV NYHA show a significant response only to continuous infusions of prostanoids) [18]. In our recent experience, macitentan (an endothelin receptor antagonist) is the treatment of choice for patients in classes II and III NYHA [31].

ILD remains one of the main causes of mortality in SSc, especially in patients with the diffuse form [77]; therefore treatment with immunosuppressive drugs ought to be initiated in the early inflammatory stage (alveolitis) to prevent the deterioration of lung function. We currently prefer mycophenolate mofetil over cyclophosphamide owing to the toxicity of the latter $[39,78]$. Stem cell transplantation procedures are only performed in few specialized centers now [46]. In case of poor clinical response or intolerance, patients with ILD are switched to rituximab, a specific anti-CD20 monoclonal antibody [79]. Rituximab also appears to be effective in treating chronic arthritis, another possible complication in patients with diffuse cutaneous SSc.

Cardiomyopathy, another visceral complication of diffuse SSc, should be treated even in its asymptomatic phase. However, early diagnosis is challenging and requires cardiac 
MRI. The therapeutic approach is similar of ILD and includes immunosuppressants such as cyclophosphamide, azathioprine or rituximab [80,81].

Scleroderma renal crisis is a rare organ involvement characterized by rapidly progressive kidney failure that may result in patients requiring dialys is within few weeks. The therapy is based on the use of maximum tolerated doses of ACE inhibitors to reduce over-activation of the renin-angiotensin system, to control arterial hypertension and to prevent dialysis [47]. SRC can be triggered by vasoconstrictors such as calcineurin inhibitors or corticosteroids at high doses, and their use should therefore be avoided altogetherin scleroderma patients [49]. The therapeutic protocol for SRC that is performed in the Padua Rheumatology Unit consists of a combination of high dose ACE-inhibitors coupled with repeated plasma-exchange sessions, especially when it is complicated by renal microangiopathic hemolytic anemiaand/or thrombocytopenia [82].

In conclusion, SSc therapy must be tailored to the patient based on the disease subset and organ involvement. 


\section{References}

1. Desbois AC, Cacoub P. Systemic sclerosis: An update in 2016. Autoimmun Rev.

2016;15:417-26.

2. Ferri C, Sebastiani M, Lo Monaco A, Iudici M, Giuggioli D, Furini F, Manfredi A, Cuomo G, Spinella A, Colaci M, Govoni M, Valentini G. Systemic sclerosis evolution of disease pathomorphosis and survival. Our experience on Italian patients' population and review of the literature. Autoimmun Rev. 2014;13:1026-34.

3. Bryan C, Howard Y, Brennan P, et al. Prediction of five-years survival following presentation with scleroderma: Development of a simple model using three diseases factors at first visit. Arthritis Rheum. 1999 42:2660-5.

4.Tyndall AJ, Bannert B, Cozzi F, et al. Causes and risk factors for death in systemic sclerosis: a study from the EULAR scleroderma Trials and Research (EUSTAR) database. Ann Rheum Dis. 201015

5. Avouac J, Kowal-Bielecka O, Landewe R, et al. European League Against Rheumatism (EULAR) Scleroderma Trial and Research group (EUSTAR) recommendations for the treatment of systemic sclerosis: methods of elaboration and results of systematic literature research. Ann Rheum Dis. 2009 68: 629-34.

6. Kowal-Bielecka O, Landewé R, Avouac J, et al. EULAR recommendations for the treatment of systemic sclerosis: a report from the EULAR Scleroderma Trials and Research group (EUSTAR). Ann Rheum Dis. 2009 68: 620-8. 
7. Otylia Kowal-Bielecka, Jaap Fransen, Jerome Avouac, Mike Becker, Agnieszka Kulak, Yannick Allanore, Oliver Distler, Philip Clements, Maurizio Cutolo, Laszlo Czirjak, Ulf Müller-Ladner,15 EUSTAR Coauthors. Update of EULAR recommendations for the treatment of systemic sclerosis. Ann Rheum Dis 2016;0:1-13

8.Thompson AE, Shea B, Welch V, et al. Calcium-channel blockers for Raynaud's phenomenon in systemic sclerosis. Arthritis Rheum 2001;44:1841-7.

9. Ettinger WH, Wise RA, Schaffhauser D, et al. Controlled double-blind trial of dazoxiben and nifedipine in the treatment of Raynaud's phenomenon. Am J Med $1984 ; 77: 451-6$.

10. Kahan A, Weber S, Amor B, et al. Calcium entry blocking agents in digital vasospasm (Raynaud's phenomenon). Eur Heart J 1983;4(Suppl C):123-9.

11 Kahan A, Foult JM, Weber S, et al. Nifedipine and alpha 1-adrenergic blockade in Raynaud's phenomenon. Eur Heart J 1985;6:702-5.

12 Kahan A, Amor B, Menkès CJ, et al. Nicardipine in the treatment of Raynaud's phenomenon: a randomized double-blind trial. Angiology 1987;38:333-7.

13. Rademaker M, Cooke ED, Almond NE, et al. Comparison of intravenous infusions of iloprost and oral nifedipine in treatment of Raynaud's phenomenon in patients with systemic sclerosis: a double blind randomised study. BMJ 1989;298:561-4.

14. Rodeheffer RJ, Rommer JA, Wigley F, et al. Controlled double-blind trial of nifedipine in the treatment of Raynaud's phenomenon. N Engl J Med 1983;308:880-3. 
15. Meyrick Thomas RH, Rademaker M, Grimes SM, et al. Nifedipine in the treatment of Raynaud's phenomenon in patients with systemic sclerosis. Br J Dermatol $1987 ; 117: 237-41$.

16. Roustit M, Blaise S, Allanore $\mathrm{Y}$, et al. Phosphodiesterase-5 inhibitors for the treatment of secondary Raynaud's phenomenon: systematic review and meta-analysis of randomised trials. Ann Rheum Dis 2013;72:1696-9.

17. Herrick AL, van den Hoogen F, Gabrielli A, et al. Modified-release sildenafil reduces Raynaud's phenomenon attack frequency in limited cutaneous systemic sclerosis. Arthritis Rheum 2011;63:775-82.

18 Fries R, Shariat K, von Wilmowsky H, et al. Sildenafil in the treatment of Raynaud's phenomenon resistant to vasodilatory therapy. Circulation 2005;112:2980-5.

19 Schiopu E, Hsu VM, Impens AJ, et al. Randomized placebo-controlled crossover trial of tadalafil in Raynaud's phenomenon secondary to systemic sclerosis. J Rheumatol 2009;36:2264-8.

20 Shenoy PD, Kumar S, Jha LK, et al. Efficacy of tadalafil in secondary Raynaud's phenomenon resistant to vasodilator therapy: a double-blind randomized cross-over trial. Rheumatology (Oxford) 2010;49:2420-8.

21 Agarwal V, Ghosh P, Sharma A, et al. Efficacy of tadalafil in Raynaud's phenomenon secondary to systemic sclerosis: a double-blind randomized placebo-controlled parallel group multicentric study (abstract). Arthritis Rheum 2010;62(Suppl 10):S872. 
22 Caglayan E, Axmann S, Hellmich M, et al. Vardenafil for the treatment of Raynaud phenomenon: a randomized, double-blind, placebo-controlled crossover study. Arch Intern Med 2012;172:1182-4.

23. Coleiro B, Marshall SE, Denton CP, et al. Treatment of Raynaud's phenomenon with the selective serotonin reuptake inhibitor fluoxetine. Rheumatology (Oxford) 2001;40:1038-43

24. Wigley FM, Seibold JR, Wise RA, et al. Intravenous iloprost treatment of Raynaud's phenomenon and ischemic ulcers secondary to systemic sclerosis. J Rheumatol 1992;19:1407-14.

25 Wigley FM, Wise RA, Seibold JR, et al. Intravenous iloprost infusion in patients with Raynaud phenomenon secondary to systemic sclerosis. A multicenter, placebocontrolled, double-blind study. Ann Intern Med 1994;120:199-206.

26 Black CM, Halkier-Sørensen L, Belch JJ, et al. Oral iloprost in Raynaud's phenomenon secondary to systemic sclerosis: a multicentre, placebo-controlled, dosecomparison study. Br J Rheumatol 1998;37:952-60.

27 Seibold JR, Wigley F, Schiopu E, et al. Digital ischemic ulcers in scleroderma treated with oral treprostinil diethanolamine: a randomized, double-blind, placebocontrolled, multicenter study [abstract]. Arthritis Rheum 2011;63(10 Suppl):S968.

28 Tingey T, Shu J, Smuczek J, et al. Meta-analysis of healing and prevention of digital ulcers in systemic sclerosis. Arthritis Care Res (Hoboken) 2013;65:1460-71. 
29. Korn JH, Mayes M, Matucci Cerinic M, et al. Digital ulcers in systemic sclerosis: prevention by treatment with bosentan, an oral endothelin receptor antagonist. Arthritis Rheum 2004;50:3985-93.

30. Matucci-Cerinic M, Denton CP, Furst DE, et al. Bosentan treatment of digital ulcers related to systemic sclerosis: results from the RAPIDS-2 randomised, double-blind, placebo-controlled trial. Ann Rheum Dis 2011;70:32-8.

31 Pulido T, Adzerikho I, Channick RN, et al. Macitentan and morbidity and mortality in pulmonary arterial hypertension. N Engl J Med 2013;369:809-18.

32 Ghofrani HA, Distler O, Gerhardt F, et al. Treatment of pulmonary arterial hypertension (PAH): updated Recommendations of the Cologne Consensus Conference 2011. Int J Cardiol 2011;154(Suppl 1):S20-33.

33 Taichman DB, Ornelas J, Chung L, et al. Pharmacologic therapy for pulmonary arterial hypertension in adults: CHEST guideline and expert panel report. Chest 2014;146:449-75

34.Badesch DB, Tapson VF, McGoon MD, et al. Continuous intravenous epoprostenol for pulmonary hypertension due to the scleroderma spectrum of disease. A randomized, controlled trial. Ann Intern Med 2000;132:425-34.

35. van den Hoogen FH, Boerbooms AM, Swaak AJ, et al. Comparison of methotrexate with placebo in the treatment of systemic sclerosis: a 24 week randomized double-blind trial, followed by a 24 week observational trial. Br J Rheumatol 1996;35:364-72. 
36 Pope JE, Bellamy N, Seibold JR, et al. A randomized, controlled trial of methotrexate versus placebo in early diffuse scleroderma. Arthritis Rheum $2001 ; 44: 1351-8$.

37 Johnson SR, Feldman BM, Pope JE, et al. Shifting our thinking about uncommon disease trials: the case of methotrexate in scleroderma. J Rheumatol 2009;36:323-9.

38 Lateef O, Shakoor N, Balk RA. Methotrexate pulmonary toxicity. Expert Opin Drug Saf 2005;4:723-30.

39 Tashkin DP, Elashoff R, Clements PJ, et al. Cyclophosphamide versus placebo in scleroderma lung disease. N Engl J Med 2006;354:2655-66.

40 Hoyles RK, Ellis RW, Wellsbury J, et al. A multicenter, prospective, randomized, double-blind, placebo-controlled trial of corticosteroids and intravenous cyclophosphamide followed by oral azathioprine for the treatment of pulmonary fibrosis in scleroderma. Arthritis Rheum 2006;54:3962-70.

41 Goldin J, Elashoff R, Kim HJ, et al. Treatment of scleroderma-interstitial lung disease with cyclophosphamide is associated with less progressive fibrosis on serial thoracic high-resolution CT scan than placebo: findings from the scleroderma lung study. Chest 2009;136:1333-40.

42 Tashkin DP, Elashoff R, Clements PJ, et al. Effects of 1-year treatment with cyclophosphamide on outcomes at 2 years in scleroderma lung disease. Am J Respir Crit Care Med 2007;176:1026-34. 
43 Roth $\mathrm{MD}$, Tseng $\mathrm{CH}$, Clements $\mathrm{PJ}$, et al. Predicting treatment outcomes and responder subsets in scleroderma-related interstitial lung disease. Arthritis Rheum 2011;63:2797-808.

44 Lynch JP III, McCune WJ. Immunosuppressive and cytotoxic pharmacotherapy for pulmonary disorders. Am J Respir Crit Care Med 1997;155:395-420.

45 Burt RK, Shah SJ, Dill K, et al. Autologous non-myeloablative haemopoietic stemcell transplantation compared with pulse cyclophosphamide once per month for systemic sclerosis (ASSIST): an open-label, randomised phase 2 trial. Lancet 2011;378:498-506.

46 van Laar JM, Farge D, Sont JK, et al. Autologous hematopoietic stem cell transplantation vs intravenous pulse cyclophosphamide in diffuse cutaneous systemic sclerosis: a randomized clinical trial. JAMA 2014;311:2490-8.

47. Lopez-Ovejero JA, Saal SD, D'Angelo WA, et al. Reversal of vascular and renal crises of scleroderma by oral angiotensin-converting-enzyme blockade. N Engl J Med 1979;300:1417-19.

48. Steen VD, Costantino JP, Shapiro AP, et al. Outcome of renal crisis in systemic sclerosis: relation to availability of angiotensin converting enzyme (ACE) inhibitors. Ann Intern Med 1990;113:352-7.

49 Steen VD, Medsger TA Jr. Long-term outcomes of scleroderma renal crisis. Ann Intern Med 2000;133:600-3. 
50 Teixeira L, Mouthon L, Mahr A, et al. Mortality and risk factors of scleroderma renal crisis: a French retrospective study of 50 patients. Ann Rheum Dis 2008;67:110-16.

51 Guillevin L, Bérezné A, Seror R, et al. Scleroderma renal crisis: a retrospective multicentre study on 91 patients and 427 controls. Rheumatology (Oxford) $2012 ; 51: 460-7$.

52. Steen VD, Medsger TA Jr. Case-control study of corticosteroids and other drugs that either precipitate or protect from the development of scleroderma renal crisis. Arthritis Rheum 1998;41:1613-19.

53 Pakozdi A, Wilson H, Black CM, et al. Does long term therapy with lansoprazole slow progression of oesophageal involvement in systemic sclerosis? Clin Exp Rheumatol 2009;27(Suppl 54):5-8.

54 Chiba N, De Gara CJ, Wilkinson JM, et al. Speed of healing and symptom relief in grade II to IV gastroesophageal reflux disease: a meta-analysis. Gastroenterology 1997;112:1798-810.

55 Donnellan C, Sharma N, Preston C, et al. Medical treatments for the maintenance therapy of reflux oesophagitis and endoscopic negative reflux disease. Cochrane Database Syst Rev 2005;(2):Cd003245.

56 Sigterman KE, van Pinxteren B, Bonis PA, et al. Short-term treatment with proton pump inhibitors, H2-receptor antagonists and prokinetics for gastro-oesophageal reflux disease-like symptoms and endoscopy negative reflux disease. Cochrane Database Syst Rev 2013;(5):Cd002095. 
57 Ali T, Roberts DN, Tierney WM. Long-term safety concerns with proton pump inhibitors. Am J Med 2009;122:896-903.

58. Acosta A, Camilleri M. Prokinetics in gastroparesis. Gastroenterol Clin North Am $2015 ; 44: 97-111$.

59. Parodi A, Sessarego M, Greco A, et al. Small intestinal bacterial overgrowth in patients suffering from scleroderma: clinical effectiveness of its eradication. Am $\mathrm{J}$ Gastroenterol 2008;103:1257-62.

60. Marie I, Ducrotté P, Denis P, et al. Small intestinal bacterial overgrowth in systemic sclerosis. Rheumatology (Oxford) 2009;48:1314-19.

61 Khanna D, Denton CP, Jahreis A, et al. Safety and efficacy of subcutaneous tocilizumab in adults with systemic sclerosis (faSScinate): a phase 2, randomised, controlled trial. Lancet 2016;387:2630-40.

62 Clements PJ, Tashkin D, Roth M, et al. The Scleroderma Lung Study II (SLS II) shows that both oral cyclophosphamide (CYC) and mycophenolate mofetil (MMF) are efficacious in treating progressive interstitial lung disease (ILD) in patients with systemic sclerosis (SSc) [abstract]. Arthritis Rheumatol 2015;67(Suppl 10).

63 LeRoy EC, Black C, Fleischmajer R, Jablonskas S, Kireg T, Medsger TA Jr et al. Scleroderma (systemic sclerosis): classification, subsets and pathogenesis. J Rheumatol $1988 ; 15: 202-5$. 
64 Domsic DT. Scleroderma: the role of serum autoantibodies in defining specific clinical phenotyper and organ system involvement. Curr Opin Rheumatol 2014;26:646652.

65Chaisson NF, Hassoun PM. Systemic sclerosis-associated pulmonary arterial hypertension. Chest 2013;144:1346-56.

66Ferri C, Valentini G, Cozzi F, Sebastiani M, Michelassi M, La Montagna G et al. Systemic Sclerosis: Demographic, Clinical, and Serologic Features and Survival in 1,012 Italian Patients. Medicine (Baltimore) 2002;8:139-53.

67Le EN, Wigley FM, Shah AA, Boin F, Hummers LK. Long-term experience of mycophenolate mofetil for treatment of diffuse cutaneous systemic sclerosis. Ann Rheum Dis 2011;70:1104-7.

68Cozzi F, Marson P, Rosada M, De Silvestro G, Bullo A, Punzi L, et al. Long-term therapy with plasma exchange in systemic sclerosis: effects on laboratory markers reflecting disease activity. Transfus Apheresis Sci 2001;25:25-31.

69[10] Wigley FM, Seibold JR, Wise RA, McCloskey DA, Dole WP. Intravenous iloprost treatment of Raynaud's phenomenon and ischemic ulcers secondary to systemic sclerosis. J Rheumatology 1992; 19:1407-1414.

70Cozzi F, Pigatto E, Rizzo M, Favaro M, Zanatta E, Cardarelli S et al. Low occurrence of digital ulcers in scleroderma patients treated with bosentan for pulmonary arterial hypertension: a retrospective case-control study. Clin Rheumatol 2013;32:679-83.

71Valenzuela A and Chung L. Management of Calcinosis Associated with Systemic 
Sclerosis. Curr Treat Options in Rheum 2016;2:85-96.

72Nagaraja V, McMahan ZH, Getzug T, and Khanna D. Management of gastrointestinal involvement in scleroderma. Curr Treat Opt Rheumatol 2015;1:82-105.

73Wang SJ, La JL, Chen DY, Chen YH, Hsieh TY, Lin WY. Effects of cisapride on oesophageal transit of solids in patients with progressive systemic sclerosis. Clin Rheumatol 2002;21:43-5.

74Grace E, Shaw C, Whelan K, Andreyev HJ. Review article: small intestinal bacterial overgrowth - prevalence, clinical features, current and developing diagnostic tests, and treatment. Aliment Pharmacol Ther2013; 38:674-88

75Sobanski V, Launay D, Hachulla E, Humbert M. Current Approaches to the Treatment of Systemic-Sclerosis-Associated Pulmonary Arterial Hypertension (SscPAH). Curr Rheumatol Rep 2016;18:10.

76Humbert M, Coghlan JG, Ghofrani HA, Grimminger F, He JG, Riemekasten G et al. Riociguat for the treatment of pulmonary arterial hypertension associated with connective tissue disease: results from PATENT-1 and PATENT-2. Ann Rheum Dis 2017;76:422-426.

77Tyndall AJ1, Bannert B, Vonk M, et al. Causes and risk factors for death in systemic sclerosis: a study from the EULAR Scleroderma Trials and Research (EUSTAR) database. Ann Rheum Dis. 2010; 69:1809-15.

78 Owen C, Ngian G, Elford, Moore O, Stevens W, Nikpour M, et al. Mycophenolate mofetil is an effective and safe option for the management of systemic sclerosis- 
associated interstitial lung disease: results from the Australian Scleroderma Cohort Study. Clin Exp Rheumatol 2016; 34 (Suppl 100):170-176.

79Bosello SL, De Luca G, Rucco M, Berardi G, Falcione M, Danza et al. Long-term efficacy of B cell depletion therapy on lung and skin involvement in diffuse systemic sclerosis. Semin Arthritis Rheum 2015; 44: 428-36.

80Dinser R, Frerix M, Meier FM, Klingelb K, Rolf A. Endocardial and myocardial involvement in systemic sclerosis - is there a relevant inflammatory component? Joint Bone Spine 2013;80:320-3.

81Pieroni P, DeSantis M, Zizzo G, Bosello SL, Smaldone C, Campioni M et al. Recognizing and treating myocarditis in recent-onset systemic sclerosis heart disease: Potential utility of immunosuppressive therapy in cardiac damage progression. Semin Arthritis Rheum 2014; 43:526-35.

82 Cozzi F, Marson P, Cardarelli S, Favaro M, Tison T, Tonello M et al. Prognosis of scleroderma renal crisis: a long-term observational study. Nephrol Dial Transplant 2012; 27:4398-4403. 